\title{
Research on the Effectiveness of Exercise Therapy Treating Mental Illness
}

\author{
Shi Ying*
}

School of Physical Education Science, Nantong University, Nantong, China

\begin{abstract}
With the development of modern society, mental illness has become a high incidence of all illnesses. This paper describes the positive role of sport in the rehabilitation of mental illness played from exercise physiology and psychology. And for the various manifestations of mental illness, introduce a number of specific exercise therapies. Finally, we chose 10 student volunteers as our experiment subjects. After one week of exercise therapy, compared the mental state indexes of before and after motion treatment. The final results showed that exercise therapy can significantly improve the psychological status of college students.
\end{abstract}

Keywords: Exercise therapy, mental illness, physiological of sports, psychology of sports.

\section{INTRODUCTION}

According to a survey conducted by the Chinese Center for Disease Control released by the Mental Health Center, the presence of $15.8 \%-24.1 \%$ of the students have psychological problems [1], of which, about 24.7 percent of the students have different degrees of mental health disorders or mental abnormalities [2], which can induce serious accidents, suicide and homicide. Thus, the psychological impact of the disease has become a problem for college students which can not be ignored. The study of mental diseases, the development process as well as incentives, and taking effective prevention, steps and treatment, etc. has farreaching practical significance.

Various types of mental illness have occured more and more in the student population. If you can not get a reasonable treatment, it will seriously affect the normal learning and life of university students. In addition to psychological and medical treatment, we should actively explore and seek more healthy and effective adjunct to the process of the integrated use of mental health education and therapy, and integrated use they to the process of mental health education and therapy. For mental illness, in addition to the use of psychological methods, but also can combine with practical innovation, use the sport approach to treatment. More and more scholars believe that sport has a positive effect on mental health. The therapeutic effect of sports on mental health issues is as much as some of the psychological and medical treatment [3]. To sum up, including the following: 1) Physical exercise can stimulate and promote the intellectual development of students; 2) sports can train students to form a positive willpower; 3 ) sports can relieve tension, improve stress resistance; 4) sport can promote the personality of a comprehensive development; 5) sports can coordinate relationships.

The rest of the paper is organized as follows. In Section 2 , the main types, symptoms and causes of mental illness are summarized briefly. In Section 3, sports on the regulation and treatment of mental illness are described. In Section 5, the one data processing method: variance is described in detail. In Section 5, experiments are presented and the results are discussed. Finally, a conclusion is provided in Section 6.

\section{THE MAIN TYPES, SYMPTOMS AND CAUSES OF MENTAL ILLNESS}

Students mental illness is mainly in interpersonal bad; uncomfortable interacting with others and a sense of inferiority; withdrawn, bizarre; Duirenduishi indifference; like a loner; self-enclosed; poor communication with people and communication; often accompanied by depression, obsessive-compulsive, anxiety, paranoia, paranoia and other psychological disorder. Main types of students mental illness includes depression, obsessive compulsive disorder, anxiety, paranoia, phobias, paranoia, neurasthenia, wherein depression, obsessive compulsive disorder, anxiety and paranoia are most common [4].

\subsection{Symptoms}

\subsubsection{Depression}

The main manifestations are: depression, the patient feels bad, pessimistic mood of depression, not relate to people, own estimates too low, believe that small difficulties are insurmountable, work can not be qualified, interested in nothing, showing slow, dull, lack of energy, all day worried, a worried frown, down sigh or few words, struggled to live and often inferiority guilt from sin [5]. 


\subsubsection{Obsessive-Compulsive Disorder}

The main manifestations are: usually frequent sense of insecurity and inadequate, excessive self-restraint, self overly concerned, too strong sense of responsibility, often pursuit of perfection, while too rigid, lacking the ability to improvise, too stiff and cautious.

\subsubsection{Anxiety Disorder}

The main manifestations are that patients make too serious estimates for their own health and objective circumstances. In the absence of any objective basis of the circumstances, they feel the pinch, even if the multiexplanation, it does not eliminate their concerns.

\subsection{Cause Analysis}

Students are at the crossroads of life, their outlook on life and world outlook are not finalized and immature; physical and mental development is not enough balanced sound. Mood is very unstable. In the face of all kinds of psychological conflicts and confusion, since self-regulation is not strong, poor adaptability, it is prone to psychological disorders and mental illness [6]. Through the investigation in recent years in our school students suffering from mental illness, after analysis, we found that the main factors affecting the psychology of college students are:

1) Adaptation and ability to accept to face the new environment and new things of university;

2) Affordability to face life, learning, employment, competition and other aspects of pressure;

3) Self - control ability to face the temptation of something new networks;

4) Handling capacity to face interpersonal and emotional problems.

\section{SPORTS ON THE REGULATION AND TREAT- MENT OF MENTAL ILLNESS}

\subsection{Sports Features}

According to the survey, about 80 percent of the students within mental disease are not regular exercise [7]. For the students regularly participating in sports, the extent of the psychological pressure distress is significantly lower than the students not participating in sports. Because sports has the following characteristics:

Physical health and mental health have internal target intersection in the function. Sports is not only able to develop, enhance physical fitness, but also has the harmonious development of body and mind. Meanwhile, tough, fatigue, intense and competition is sports features. When participating in sports, there is always accompanied by a strong emotional experience and the obvious will of efforts. It helps to develop people indomitable courage, perseverance style, the collective spirit of solidarity and quick and clever, calm and decisive quality, as well as people maintain a positive attitude. For example: long distance running and other more strenuous sports, it will be able to effectively enhance the quality of students. While improving physical condition, students also can fully appreciate the joy of victory.

\subsection{Advantages of Sports Treating Mental Illness}

Sports conditioning and treatment of mental illness has the following advantages:

1) Easy to accept for patients. The vast majority of patients do not recognize his illness, but do not want to psychotherapy institutions to treat, but the sport is easy to accept treatment. Because patients do not feel the patient's treatment, be treated in pleasant activities;

2) Quick. Sport not only can regulate psychological, but also to improve the physiological level, reaching physiological to help cure mental illness;

3) No side effects, a small rebound. Through sport means to regulate the treatment, small likelihood of disease recurrence, but there is no danger;

4) Ease of self-regulation, treatment, easy sport means. Without being limited by medical conditions, but without the need to spend money, easy to self-regulation.

\subsection{Fundamentals of Sports Treating Mental Illness}

Brain and muscle of information of people is bidirectional conduction [8]. Nervous excitement can be passed from the brain to the muscles, it can also spread to the brain from the muscles. More muscle activity, more impulse from transmitted from muscle to brain, higher level of the brain, and emotions will run high. Conversely the more relaxed the muscles, less impulse from transmitted from muscle to brain, reduces the excitability of the brain, emotions would not be high. Sport has been able to effectively regulate the psychological mood, which followes this principle.

\subsection{The Means and Methods of Sports Treating Mental Illness}

Sport can divert people's attention, vent emotions, change interest, relax tense, psychological and make emotional tend to be stable; and different intensity and speed of physical activity, can interrupt and destroy mental patients negative psychological guide, consume a lot of mental energy of patients suffering from mental illness accumulated [9-10]. Therefore, in the use of sports means to treat sick students, according to the prevalence of different types of patients, combining different characteristics of each sport, thereby eliminating morbid psychology of sick students has been formed and restore health.

For example: for the treatment of depression, you can select fun and skill collective projects, such as: soccer, volleyball, basketball, Shuttlecock, table tennis; For the treatment of obsessive-compulsive disorder can choose easy, fun and entertainment strong sports, such as aerobics, swimming, hiking, skiing, ice skating; For the treatment of anxiety disorders can choose easy, fun strong interest in patient activity or project, for example: badminton, table tennis, volleyball, basketball, swimming, hiking, etc; For the treatment of paranoia, can choose a collective project needed to collaborate together to accomplish, for example, $4 \times 100$ - 
$\mathrm{m}$ relay events, tug of war, volleyball and so on; For the treatment of neurasthenia, can choose these patient are interested in or sports of heavy ideas, such as: swimming, tai chi and qigong.

\section{DATA PROCESSING METHOD: VARIANCE}

The variance is a parameter that describes, in part, either the actual probability distribution of an observed population of numbers, or the theoretical probability distribution of a not-fully-observed population from which a sample of numbers has been drawn. In the latter case, a sample of data from such a distribution can be used to construct an estimate of the variance of the underlying distribution; in the simplest cases this estimate can be the sample variance.

The variance of a random variable $X$ is its second central moment, the expected value of the squared deviation from the mean $\mu=E[X]$ :

$$
\operatorname{Var}(\mathrm{X})=E\left[(\mathrm{X}-\mu)^{2}\right]
$$

This definition encompasses random variables that are discrete, continuous, neither, or mixed. The variance can also be thought of as the covariance of a random variable with itself:

$$
\operatorname{Var}(\mathrm{X})=\operatorname{Cov}(\mathrm{X}, \mathrm{X})
$$

If the random variable $\mathrm{X}$ is continuous with probability density function $\mathrm{f}(\mathrm{x})$, then the variance is given by

$$
\operatorname{Var}(\mathrm{X})=\sigma^{2}=\int(\mathrm{x}-\mu)^{2} f(\mathrm{x}) \mathrm{dx}
$$

where $\mu$ is the expected value,

$$
\mu=\int \mathrm{x} f(\mathrm{x}) \mathrm{dx}
$$

If the random variable $\mathrm{X}$ is discrete with probability mass function $x_{1}->p_{1}, \ldots, x_{n}->p_{n}$, then

$$
\operatorname{Var}(\mathrm{X})=\sum_{i=1}^{n} p_{i} \cdot\left(\mathrm{x}_{i}-\mu\right)^{2}=\sum_{i=1}^{n}\left(p_{i} \cdot \mathrm{x}_{i}^{2}\right)-\mu^{2}
$$

where $\mu$ is the expected value, i.e.

$$
\mu=\sum_{i=1}^{n} p_{i} \cdot x_{i}
$$

\section{EXPERIMENTAL METHODS AND RESULTS}

First make an exercise program. One study of psychologist Thayer showed that: Optimism, happiness and good comfort occurred at about 10:00 in the morning, or after a relaxing walk, which is higher than at 15:00-16: 00 time. Thus, one exercise program is: arrange a jogging every day, at 10:00 am or 17:00 pm; you can maneuver arranged according to class situation. Every jogging distance control at $2 \mathrm{~km}$ to $4 \mathrm{~km}$; Time control in about 30 minutes; Speed is maintained at $150 \mathrm{~m} / \mathrm{min}$. If cruising in track and field run feel irritable, you can also change the venue in the outdoors, such as better traffic environment around the island ring road or the road. Running while converting the immediate environment, to avoid irritable mood appears. Into the summer, you can expand sports, such as swimming, cycling and other activities. But we must control the time and energy, do not need to turn out to be exhausted themselves.

The subjects were 10 male students of our school, where average age is 20.6 , average height is 170.8 , average weight is 64.6.

The pleasant mood result before and after exercise therapy is as shown in Fig. (1). We can find that after exercise therapy the pleasant mood indicators of ten students are all

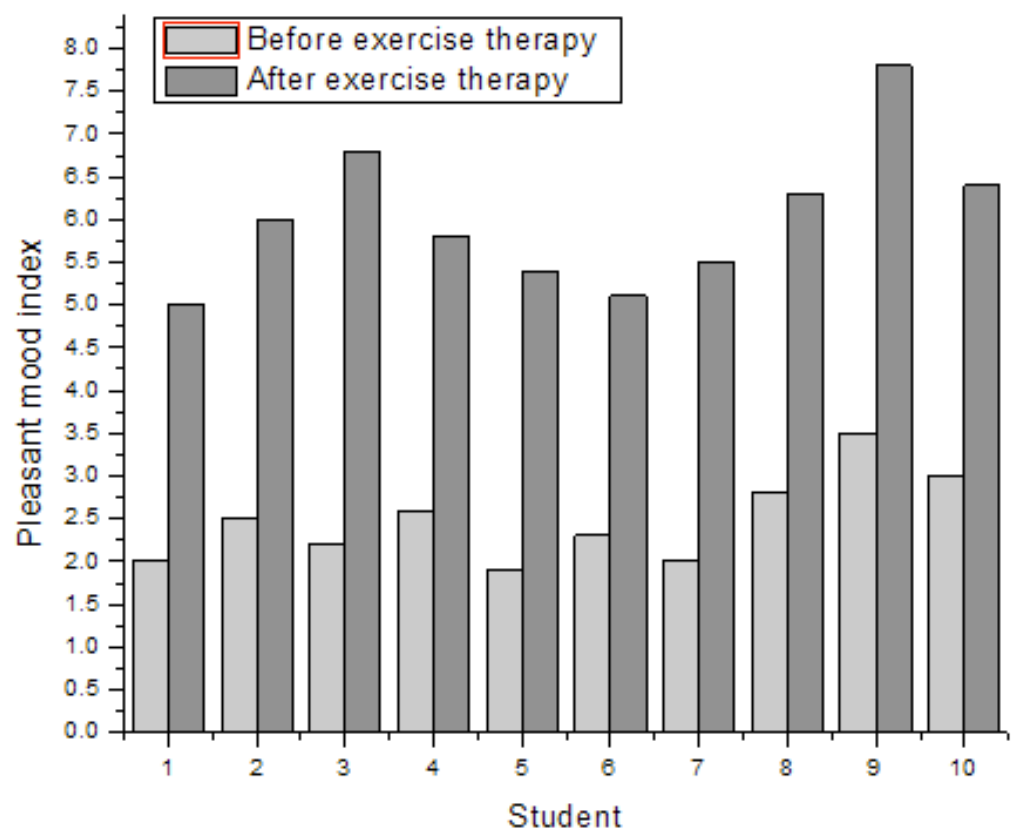

Fig. (1). Pleasant mood index before and after exercise therapy. 


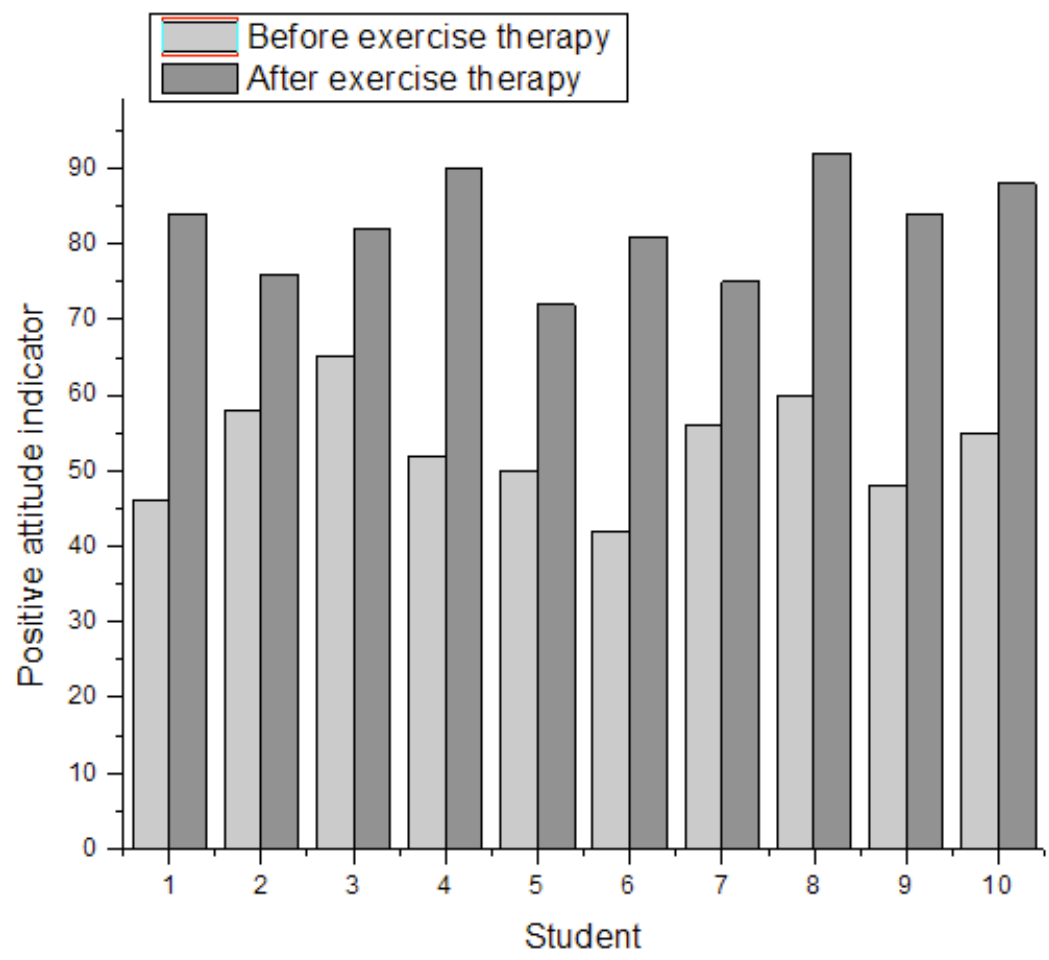

Fig. (2). Positive attitude indicator before and after exercise therapy.

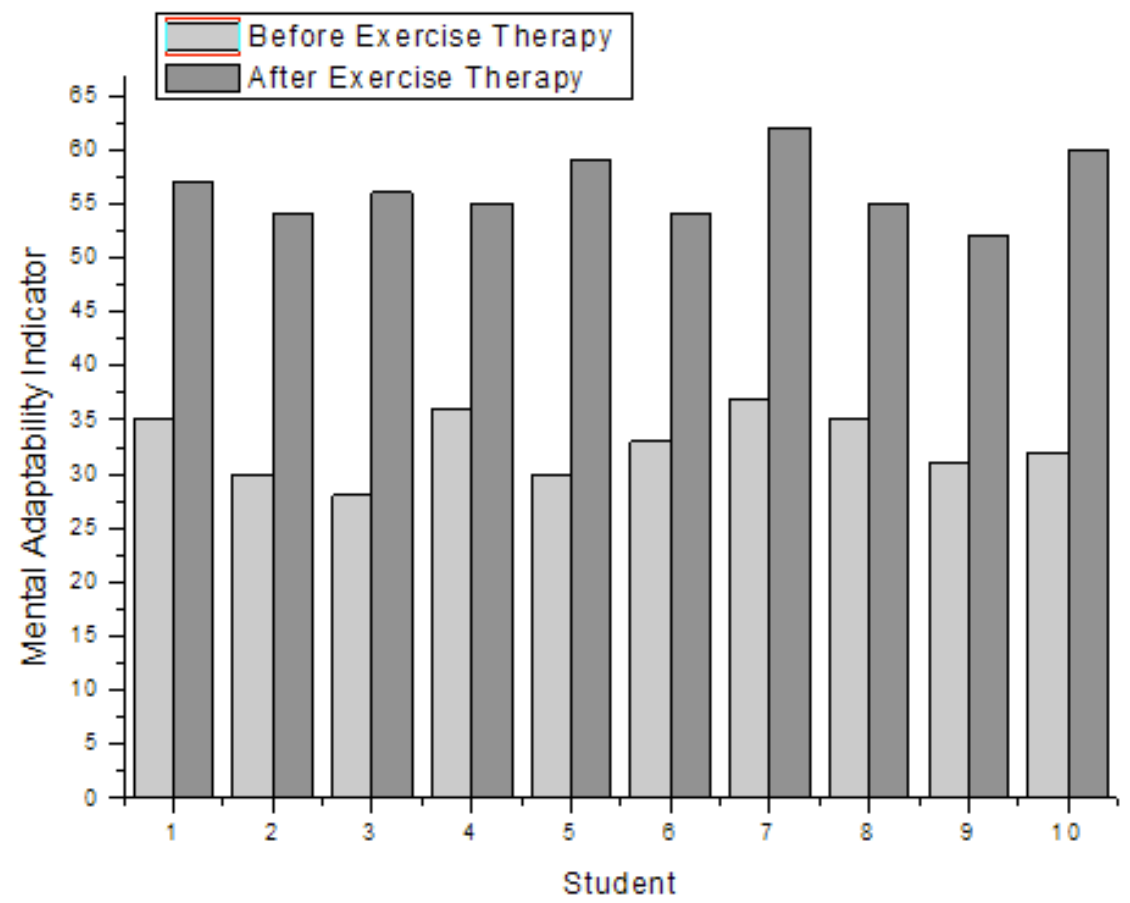

Fig. (3). Mental adaptability indicator before and after exercise therapy.

increased by at least 1.5 times. The positive attitude result before and after exercise therapy is as shown in Fig. (2). We can find that after exercise therapy the positive attitude indicators of ten students are all increased by at least 0.4 times. And at last the mental adaptability result before and after exercise therapy is as shown in Fig. (3). We can find that after exercise therapy the mental adaptability indicators of ten students are all increased by at least 1.8 times.

\section{CONCLUSION}

With the development of modern society, mental illness has become a high incidence of mental illness. This paper describes the positive role of sport in the rehabilitation of mental illness played from exercise physiology and psychology. And for the various manifestations of mental illness, introduce a number of specific exercise therapies. Finally, 
we chose 10 student volunteers as our experiment subjects. After one week of exercise therapy, compared the mental state indexes of before and after motion treatment. The final results showed that exercise therapy can significantly improve the psychological status of college students.

\section{CONFLICT OF INTEREST}

The author confirms that this article content has no conflict of interest.

\section{ACKNOWLEDGEMENTS}

This work is supported by 2013 scientific research project of Nantong University (2013NTKY021), Natural Science Foundation of of Nantong University (2013NTNSF069).

\section{REFERENCES}

[1] W. Hou, D. Medynski, S. Wu, X. Lin, L.Y. Li, "VEGI-192, a new isoform of TNFSF15, specifically eliminates tumor vascular endothelial cells and suppresses tumor growth," Clin Cancer Res, vol. 11 , no. 15 , pp. 5595-5602, 2005.
[2] L.J. Metheny-Barlow, and L. Li, "Vascular endothelial growth inhibitor (VEGI), an endogenous negative regulator of angiogenesis," Semin Ophthalaol, vol. 21, no. 1, pp. 49-58, 2006.

[3] S. Srettabmjong, "A fatal heroin addict with myocardial lesion," $J$ Med Assoc Thai, vol. 92, no. 2, pp. 279-83, 2009.

[4] P.E. Davis, H. Liddiard, and T. M. McMiian, "Neuropsychological deficits and opiateabuse," Drug Alcohol Depend, vol. 67, pp. 105108, 2012.

[5] R. Dettmeyer, K. Friedrich, P. Schmidt, and B. Madea, "Heroinassociated myocardial damagesconventional and immimohistochemical investigations," Forensic SciInt, vol. 187, no. 1-3, pp. 4246, doi: 10.1016/j.forsciint.2009.02.014, 2009.

[6] A.J. Wolff, and A.E. Donnell, "Pulmonary effects of illicit drug use," Clin Chest Med, vol. 25, no. 1, pp. 203-16, 2004

[7] J. Yu, S. Tian, L. Metheny-Barlow, L.J. Chew, A.J. Hayes, H. Pan, G.L. Yu, and L.Y. Li, "Modulation of endothelial cell growth arrest and apoptosis by vascular endothelial growth inhibitor," Circ Res, vol. 89, no. 12, pp. 1161-1167, 2011.

[8] S. Strandberg, P. Nordstrom, R. Lorentzon, and M. Lorentzon, "Vitamin D receptor start codon polymorphism (FokI) is related to bone mineral density in healthy adolescent boys," J. Bone Miner Metab, vol. 21, no. 2, pp. 109-113, 2003.

[9] M. Z. Mintzer, M.L. Copersino, and M.L. Stitzer, "Opioid abuse and cognitive performance," Drug Alcohol Depend, vol. 78, pp. 225-30, 2005.

[10] S. Aslam, F. Imani, and J. Missri, "Clenbuterol-contaminated heroin: cardiovascular and metabolic effects. A caseseries and review," Conn Med, vol. 70, no. 1, pp. 5-11, 2006.

(C) Shi Ying; Licensee Bentham Open.

This is an open access article licensed under the terms of the (https://creativecommons.org/licenses/by/4.0/legalcode), which permits unrestricted, noncommercial use, distribution and reproduction in any medium, provided the work is properly cited. 